Editor: Dr Mark Levy
Editorial Board:
Dr Chris Griffiths
Dr John Haughney
Dr Robert McKinley
Dr Paul Stephenson
Statistical Adviser:
Professor Peter Kelly
International Editorial
Advisers:
Professor Onno van Schayck
Professor James Reid

Asthma in General Practice is published on behalf of the General Practitioners In Asthma Group (GPIAG) by:

Strategic Medical Publishing Action International House Crabtree Office Village Eversley Way, Egham Surrey TW20 8RY

The GPIAG is independent of any commercial company. However, it does receive an educational grant from Allen \& Hanburys Ltd to finance the group Secretariat, Annual Scientific Meeting, Research Unit and this journal.

\section{ISSN 0968-039X}

Journals Manager:

Jane Mortlock

Research Editor:

Christine Drewienkiewicz

The views expressed in this journal are not necessarily those of the General Practitioners In Asthma Group, the publisher or Allen \& Hanburys Ltd.

Editorial decisions are independent of commercial restraints.

(C) GPIAG Committee. All rights reserved. No part of this publication may be reproduced, stored in a retrieval system or transmitted, in any form or by any means, without the prior permission of the GPIAG Committee.

Correspondence concerning the journal should be addressed to the Editor

This journal is sent to members of the GPIAG, UK primary care faculties and NHS postgraduate centres. It is available for subscription from the publishers Strategic Medical Publishing Ltd.

For further information about the General Practitioners In Asthma Group, write to:

GPIAG Secretariat, The Medical Marketing Interface Bath Brewery, Toll Bridge Road, Bath BA1 7DE.

\title{
General Practice and Primary Care Group
}

\section{A new scientific group is set up by the European Respiratory Society}

\author{
CP van Schayck and ML Levy
}

$\coprod_{\text {he } 19}^{\text {ris }}$ rish, English and Dutch GPs and researchers working in the field of asthma and COPD in primary care, participated in a joint symposium at the 1998 WONCA Conference, in Dublin. During this meeting, we took the initiative to set up a European scientific group of primary care within the European Respiratory Society (ERS). This was supported by the Executive Committee of the ERS and subsequently unanimously approved by the Clinical Assembly business meeting in Madrid in October. This was accepted at the post-congress Executive Committee Meeting. Our scientific group is called the General Practice and Primary Care Group (GPPCG) and we are very proud to be the first officers of this group (Chairman and Secretary).

This initiative has been strongly supported by a recent plan for cooperation between the European Society of General Practice/Family Medicine (ESGP/FM) and the ERS.

\section{WHY THIS GROUP?}

The need for cooperation and consultation on respiratory primary care research within European countries is growing. Research activities and education on asthma and COPD in general practice have grown enormously in the last few decades.

\section{THE AIMS OF THE GPPCG}

The GPPCG aims to address the needs of health professionals who work within the primary care sector caring for people with respiratory disease, with a special focus on asthma and COPD.

We will also endeavour to improve the management of respiratory disease across the primary/secondary care interface. This will include sharing research information and the practical application of evidencebased medicine through lessons learned in primary and secondary care. The main difference between primary and secondary care is that primary care physicians see patients at a very early stage of their disease. In most European countries primary care physicians are the first, as well as the ongoing, point of contact with the patients. Therefore, the focus of the GPPCG will be the early diagnosis and treatment of asthma and COPD and how to avoid the development of these diseases (primary and secondary prevention)

\section{MAIN FIELDS OF RESEARCH INTEREST}

There are several fields of interest to the GPPCG. The following list describes some areas of particular importance.

- Acute management of respiratory diseases in the pre-hospital setting.

- Coping with respiratory diseases in their early stages of development. Early intervention and prevention policies in these conditions.

- Addressing epidemiological issues related to record-keeping in primary care. Development of useful primary care data sets over long periods of time (longitudinal morbidity registration in large primary care networks).

- $\quad$ Addressing training needs for managing respiratory disease in primary care (diagnosis, treatment, follow-up, referral to secondary care).

- Different models of providing care (disease management, managed care).

- Promoting international research by generating new multinational research that applies evidencebased medicine to different primary healthcare situations in Europe.

\section{OUR PLANS}

We will be involved in the selection process for papers for the forthcoming ERS conference in Florence (August 2000) and we hope to organise a symposium within this meeting. However, we will definitely be involved in the planning phase for symposia for the following years.

\section{HOW TO PARTICIPATE}

First join the ERS! Membership of the GPPCG is open to ERS members - anyone interested in one of the fields mentioned above. We will have our yearly meetings and symposia during the ERS conference. We particularly invite primary care researchers, nurses and other healthcare providers working in the field of asthma, COPD and other respiratory diseases in primary care to join. By becoming a member of the European Respiratory Society one can choose to participate in this (or another) scientific group. Therefore, we would encourage everybody (certainly members of the General Practitioners In Asthma Group) to become a member of the ERS and so to join this scientific group. If you would like to have more information please do not hesitate to contact one of us for details. Alternatively, contact the ERS office directly.

For more information on the GPPCG, please contact any of the addresses below:

Onno van Schayck, Chairman GPPCG

Professor of Preventive Medicine

Maastricht University, Department of General

Practice, PO Box 616, 6200 MD, Maastricht, The Netherlands

Email: onno.vanschayck@hag.unimaas.nl

Mark Levy, Secretary GPPCG

Editor, Asthma in General Practice

The Kenton Bridge Medical Centre, 155-175

Kenton Road, Kenton, Middlesex HA3 0YX, UK

Email: marklevy@gpiag-asthma.org

ERS Lausanne Office

1 Bd de Grancy, CH-1006, Lausanne

Email: nathalie.bridel@ersnet.org 